compare the effect of valency on IC-mediated clearance. This FL antibody showed very similar TNF neutralization compared to the conventional PF molecule in a bioassay. To generate ICs, the anti-ID was incubated overnight with either PF or FL CZP, and the size of the resultant ICs determined by analytical ultracentrifugation (AU). The anti-ID complexes and PF and FL CZP alone were then administered IV to the mice, and the elimination of the anti-TNFs from the circulation was monitored by quantitative liquid chromatography-mass spectrometry (LC-MS) in serial plasma samples.

Results: AU analysis of the immune complexes formed between PF CZP and the anti-ID showed the presence of one peak corresponding in size to one anti-ID molecule bound to two PF molecules $\left(\sim 3.5 \times 10^{5} \mathrm{Da}\right)$. In contrast, the FL CZP/anti-ID mixture showed ICs of various sizes up to very large molecular weights $\left(>1 \times 10^{6} \mathrm{Da}\right)$, with the predominant species corresponding to a complex of two anti-IDs bound to two FL CZP molecules $\left(\sim 6 \times 10^{5} \mathrm{Da}\right)$. The in vivo studies showed that the FL CZP/anti-ID ICs were eliminated much faster ( $t_{1 / 2}=0.3$ hours) than the FL CZP alone ( $\mathrm{t}_{1 / 2}=44.5$ hours), whereas the PF CZP/anti-ID ICs were eliminated more slowly ( $t_{1 / 2}=60.5$ hours) than the PF CZP alone ( $t_{1 / 2}=19.7$ hours). Conclusions: The FL CZP molecule formed large ICs with the anti-ID, which led to much faster elimination than the FL molecule alone. This result suggests that an ADAb response to a FL antibody could lead to rapid elimination and loss of efficacy of the drug in patients. In contrast, the PF CZP/anti-ID complex had a longer half-life than the PF CZP alone, presumably because this molecule was not seen as an IC due to the presence of only one Fc. These results showed that an ADAb to a univalent biological reagent may not lead to elimination and instead, may actually increase the in vivo half-life of the molecule.

References:

[1] van Schouwenburg PA. Ann Rheum Dis 2013;72:104-9.

Acknowledgements: This study was funded by UCB Pharma. Editorial services were provided by Costello Medical Consulting.

Disclosure of Interest: J. Silva Employee of: UCB Pharma, A. Nesbitt Employee of: UCB Pharma

DOI: 10.1136/annrheumdis-2017-eular.2241

\section{FRI0194 USE OF GLORESPONSETM NF-KB-RE-LUC2P HEK293 CELLS TO MONITOR DRUG AND ANTI-DRUG ANTIBODY LEVELS IN SERUM}

B. Hernandez-Breijo ${ }^{1}$, L.Y. Bravo Gallego ${ }^{2}$, A. Martinez-Feito ${ }^{1}$, A. Jochems ${ }^{1}$, E. Olariaga ${ }^{1}$, J. Cheng ${ }^{3}$, L. Delaurière ${ }^{4}$, F. Fan ${ }^{3}$, T. Schagat ${ }^{3}$, C. Plasencia ${ }^{1}$,

A. Mezcua ${ }^{2}$, P. Nozal ${ }^{2}$, A. Balsa ${ }^{1}$, D. Pascual-Salcedo ${ }^{1}$

${ }^{1}$ Immuno-Rheumatology research group; ${ }^{2}$ Immunology, University Hospital la

Paz, Madrid, Spain: ${ }^{3}$ Promega Corporation, Madison (WI), United States;

${ }^{4}$ Promega Europe Training and Applications Laboratory (PETAL), Promega

Corporation, Charbonnières-les-Bains, France

Background: Rheumatoid Arthritis (RA) is often treated with anti-TNF $\alpha$ such as infliximab (Ifx) which in a long-term treatment can lead to the development of anti-Ifx antibodies (ATI), resulting in an interference with the drug activity. The investigation of the bioactivity of the circulating drug and antibodies present in patients sera with inflammatory diseases will allow to harmonize the different published data using both bioassays as well as immunoassays.

Objectives: To evaluate the ability of the Promega bioassay in the quantification of both Ifx and ATI in serum from RA patients.

To compare the bioassay performance between capture- and bridging-ELISA.

Methods: Serum Ifx-trough levels were determined in 50 samples from patients with RA. To measure Ifx, the bioassay uses GloResponse ${ }^{\mathrm{TM}}$ NF-KB-RE-luc2P HEK293 cell line, which responses to TNF $\alpha$ resulting in modulation of NF-KB activity (Promega Corp., Madison, USA). This is an ease on performing reporter assay (add-mix-read) that detects the serum Ifx by inhibition of the luminiscent signal due to TNF $\alpha$. The inhibition of the Ifx-driven luminescent signal is reverted by the presence of ATI in the serum. ATI concentration is determined using a standard curve obtained with a serial dilution of a serum sample known to have ATI. A relative luminescent unit (RLU) is arbitrarily defined. The immunoassay for Ifx (ELISA) captures recombinant TNF $\alpha$, via a monoclonal antibody that does not interfere with the serum Ifx binding to TNF $\alpha$. The reaction is developed with a biotinylated anti-idiotype antibody ${ }^{1}$ (Cut-off for Ifx: $0.050 \mu \mathrm{g} / \mathrm{ml}$ ). The ELISA to detect ATI takes advantage of the bivalency of most IgG subclasses, allowing the antibodies present in serum to bridge between Ifx-coated onto the plate with biotinylated Ifx in fluid phase ${ }^{1}$ (Cut-off for ATI $50 \mathrm{AU} / \mathrm{ml}$ ).

Results: Addition of TNF $\alpha$ on GloResponse cells induces the production of luciferase resulting in an increase of the luminescent signal in a dose-response. Addition of Ifx on GloResponse cells +TNF $\alpha$ decreases the production of luciferase and therefore the luminescent signal falls $\left(r^{2}=0.99\right)$. Addition of anti-Ifx (in relative units) on GloResponse cells +TNF $\alpha+$ Ifx restore the production of luciferase resulting in an increase of the luminescent signal $\left(r^{2}=0.98\right)$.

Serum Ifx concentrations were sorted into 3 groups (low, medium and high following ELISA levels). Similar number of positive Ifx results was found (30 samples, $55 \%$ by ELISA vs 28 samples, $52 \%$ by bioassay; $\kappa=0.92 ; p=0.56$ ) along with a significant Pearson correlation $(r=0.8)$ between methods. The bioassay to measure ATI activity showed lower sensitivity than ELISA (9/31, 29\% by ELISA vs $4 / 31,13 \%$ by bioassay, $k=0.53, p=0.22$ ) with a slightly less correlation for ATI levels by both methods $(r=0.26)$.

Conclusions: Bioassay using GloResponse NF-kB cell line can be performed to monitor therapeutic drug of TNF $\alpha$ blocker and are useful to detect the presence of anti-drug antibody in serum samples treated with anti-TNF $\alpha$ antibodies. Comparison with ELISA method shows in most of the case the same data. References:

[1] Pascual-Salcedo D. et al, Rheumatology, 2011.

Disclosure of Interest: None declared

DOI: 10.1136/annrheumdis-2017-eular.6352

\section{FRI0195 POINT-OF-CARE MONITORING OF ANTI-INFLIXIMAB ANTIBODIES IN PATIENTS TREATED WITH THE REFERENCE INFLIXIMAB OR CT-P13 IN ROUTINE CLINICAL PRACTICE}

A. Ametzazurra ${ }^{1}$, N. Rivera ${ }^{2}$, A. Balsa ${ }^{3}$, M.P. Arreba ${ }^{4}$, E. Ruiz ${ }^{2}$, C. Plasencia ${ }^{3}$, J. Ortiz ${ }^{4}$, D. Pascual-Salcedo ${ }^{5}$, M.C. Muñoz ${ }^{4}$, C. De Aysa ${ }^{3}$, M.J. Allande ${ }^{2}$, N. Torres ${ }^{1}$, A.M. Hernández ${ }^{1}$, X. Recalde ${ }^{1}$, A. Martínez ${ }^{1}$, D. Nagore ${ }^{1} .{ }^{1} R \& D$, Progenika-Grifols, Derio; ${ }^{2}$ Rheumatology, Basurto University Hospital, Bilbao; ${ }^{3}$ Rheumatology, la Paz University Hospital, Madrid; ${ }^{4}$ Gastroenterology, Basurto University Hospital, Bilbao; ${ }^{5}$ Immunology, la Paz University Hospital, Madrid, Spain

Background: Loss of clinical response and infusion reactions to infliximab (IFX) are associated to the development of antibodies to IFX (ATI). ATI detection is a key step of patient management. However, current techniques may require additional patient appointments for sample collection, processing and batching in centralised facilities. Test reporting usually takes several days or weeks impairing effective decision making.

Objectives: To clinically validate the use of a new rapid test to detect ATI in capillary blood in a real-life point-of-care (POC) setting where patients attend the infusion center for the reference IFX (Remicade ${ }^{\circledR}$, RMC) or CT-P13 (Inflectra ${ }^{\circledR}$, IFT, or Remsima ${ }^{\circledR}$ ) infusions.

Methods: PQ-EF1 and PQ-EF2 are prospective, observational studies designed to evaluate and compare the performance of a rapid POC test (CE-marked Promonitor ${ }^{\circledR}$ Quick Anti-IFX, Progenika, Spain) to detect ATI in routine clinical practice in rheumatic and gastroenterology patients treated with the reference IFX or the biosimilar CT-P13 attending the infusion center with the ELISA technique as a reference. The POC test is a qualitative immunochromatographic assay based on lateral flow technology to detect ATI (including biosimilar CT-P13) in either fingerprick or serum or venous whole blood. Consecutive patients (initiating or under maintenance therapy) were recruited and tested in La Paz and Basurto University hospitals with the rapid test in capillary and venous whole blood specimens immediately before the infusion. ATI test results were read visually with the POC test in 30 min, just before the patient started the infusion. Trough sera were also collected for subsequent analysis with the rapid test and benchmarked with Promonitor ${ }^{\circledR}$-Anti-IFX ELISA (Progenika, Spain). Follow-up time was 6 months. ELISA quantitative results were categorized as positive and negative to allow comparisons with the qualitative rapid test.

Results: Ninety consecutive patients were recruited (a total of 137 visits in the 6 months follow-up) accounting for a total of 137 sera, 137 fingerpricks and 71 venous whole blood samples. Overall, $8(8.9 \%)$ patients developed ATI (5 ankylosing spondylitis, 1 Crohn's disease, 1 ulcerative colitis and 1 juvenile idiopathic arthritis). ATI were detected in 5 patients treated with Remicade ${ }^{\circledR}$ and 3 treated with Inflectra ${ }^{\circledR}$. Overall agreements between fingerprick vs venous whole blood and fingerprick vs serum measured with the rapid POC test were $100 \%$ and $99 \%$, respectively. Positive (PPA) and negative (NPA) agreements between the POC test and ELISA were $91 \%$ and $99 \%$, respectively. PPA and NPA between the ELISA and the POC test in serum was $100 \%$ and $99 \%$, respectively.

Conclusions: ATI can be reliably detected in either venous or capillary circulation. Results show an almost perfect agreement between specimens and with the reference ELISA technique. ATI measurement with the POC test allows the clinician to detect ATI in a quick and fully decentralised mode facilitating immediate POC decision making.

Disclosure of Interest: A. Ametzazurra Employee of: Employee of Progenika Grifols, N. Rivera: None declared, A. Balsa: None declared, M. Arreba: None declared, E. Ruiz: None declared, C. Plasencia: None declared, J. Ortiz: None declared, D. Pascual-Salcedo: None declared, M. Muñoz: None declared, C. De Aysa: None declared, M. Allande: None declared, N. Torres Employee of: Employee of Progenika Grifols, A. Hernández Employee of: Employee of Progenika Grifols, X. Recalde Employee of: Employee of Progenika Grifols, A. Martínez Employee of: Employee of Progenika Grifols, D. Nagore Employee of: Employee of Progenika Grifols

DOI: 10.1136/annrheumdis-2017-eular.5056

\section{FRI0196 BIOSIMILARS IN THE UK: EARLY REAL WORLD DATA FROM THE BRITISH SOCIETY FOR RHEUMATOLOGY BIOLOGICS REGISTERS FOR RHEUMATOID ARTHRITIS}

D. De Cock ${ }^{1}$, K. Watson ${ }^{1}$, K.L. Hyrich ${ }^{1,2}$ on behalf of BSRBR-RA Control Centre Consortium. ${ }^{1}$ Arthritis Research UK Centre for Epidemiology, University of Manchester; ${ }^{2}$ National Institute of Health Research Manchester Musculoskeletal Biomedical Research Unit, Central Manchester NHS Foundation Trust, Manchester Academic Health Science, Manchester, United Kingdom

Background: Biosimilars, biopharmaceuticals assessed by regulatory agencies 
to have efficacy and safety similar to their reference products, were introduced to the UK market in February 2015 for rheumatoid arthritis (RA). Most research on RA biosimilars has been done in the context of clinical trials, but real world data are lacking. No national mandate exists in the UK to switch all patients from originator to biosimilars, but there are regional variations.

Objectives: This analysis aims to describe the characteristics of the first UK patients starting RA biosimilars registered with the British Society for Rheumatology Biologics Register for RA (BSRBR-RA).

Methods: Since 03/08/2015, the BSRBR-RA has captured data on patients starting biosimilars available in the UK: infliximab (Inflectra and Remsima) and etanercept (Benepali). At biosimilar start, information is captured from the hospital including demographic and clinical data, previous biologic exposure and if switching therapies, the reason for switch (as a tick box and free text). Follow-up data, including disease activity, occurrence of adverse events and changes to treatment is captured 6-monthly for 3 years and annually thereafter. Descriptive data are presented

Results: To 15/12/2016, 417 RA patients were recruited to the BSRBR-RA at point of starting a biosimilar for whom data were available for analysis on 414 participants: 47 (11\%) Inflectra, 78 (19\%) Remsima and 289 (70\%) Benepali. Of these, 138 started a biosimilar as first biologic, 242 switched directly from the originator product and 34 switched from an alternative biologic (Table). Patients switching from the originator did so after a median (IQR) of 6.7 (3.0-9.5) years and the majority had low disease activity (median DAS28 2.7 (IQR 2.0-3.9)). The switch reason was reported in $33 \%$ of patients, with cost listed as the main reason and "trust policy" included in $63 \%$ of 30 free text comments. Six-month follow-up data were available in 41 patients. Three patients on Remsima and 1 patient on Inflectra reported drug hypersensitivity reactions (rash, pruritus, hyperpigmentation), and $18 \%(6 / 34)$ of patients experienced a deterioration in their DAS28 of $>1.2$ after 6 months.

Table

\begin{tabular}{|c|c|c|c|}
\hline & Biological naive & $\begin{array}{l}\text { Switched from } \\
\text { reference product }\end{array}$ & $\begin{array}{l}\text { Not switched from } \\
\text { reference product }\end{array}$ \\
\hline Number & 138 & 242 & 34 \\
\hline \multicolumn{4}{|l|}{ Biosimilar, $n(\%)$} \\
\hline Inflectra & $3(2 \%)$ & $40(16 \%)$ & $4(12 \%)$ \\
\hline Remsima & $9(6.5 \%)$ & $65(27 \%)$ & $4(12 \%)$ \\
\hline Benepali & $126(91 \%)$ & $137(57 \%)$ & $26(76 \%)$ \\
\hline Women, $n(\%)$ & $108(78 \%)$ & $181(75 \%)$ & $28(82 \%)$ \\
\hline Age (years) & $\frac{506(780)}{56.0(48.064 .5)}$ & $\frac{101(17.0)}{67.0(57.0-72.0)}$ & $\frac{20(020)}{59.5(44.5-68.0)}$ \\
\hline Disease Duration (years) & $4.0(1.0-10.0)$ & $17.0(10.0-24.0)$ & $9.5(6.0-14.0)$ \\
\hline DAS28(CRP) & $5.9(5.3-6.5)$ & $2.7(2.0-3.9)$ & $5.1(3.5-6.2)$ \\
\hline \multicolumn{4}{|l|}{ Comorbidities } \\
\hline 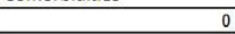 & $52(38 \%)$ & $84(35 \%)$ & $12(35 \%)$ \\
\hline 1 & $47(34 \%)$ & $84(35 \%)$ & $11(32 \%)$ \\
\hline 2 & $32(23 \%)$ & $32(13 \%)$ & $5(14 \%)$ \\
\hline $3+$ & $7(5 \%)$ & $42(17 \%)$ & $6(19 \%)$ \\
\hline \multicolumn{4}{|c|}{\begin{tabular}{|l|l|} 
Previous biological on $n(\%)$ \\
\end{tabular}} \\
\hline Enbrel & - & $137(57 \%)$ & $1(3 \%)$ \\
\hline Remicade & - & $105(43 \%)$ & $4(12 \%)$ \\
\hline Kineret & - & & $1(3 \%)$ \\
\hline Humira & - & - & $7(21 \%)$ \\
\hline Mabthera & - & - & $1(3 \%)$ \\
\hline Orencia & - & - & $4(12 \%)$ \\
\hline Simponi & . & - & $4(12 \%)$ \\
\hline RoActemra & - & - & $6(18 \%)$ \\
\hline Cimzia & - & - & $6(18 \%)$ \\
\hline \multicolumn{4}{|c|}{\begin{tabular}{|l|l|} 
Reasons to switch, $n(\%)$ & \\
\end{tabular}} \\
\hline Cost factors & $6(86 \%)$ & $107(86 \%)$ & $2(50 \%)$ \\
\hline Clinical indication & - & $5(4 \%)$ & $1(25 \%)$ \\
\hline Patient choice & - & $1(1 \%)$ & $1(50 \%)$ \\
\hline Other & $1(11 \%)$ & $11(9 \%)$ & \\
\hline Follow-up data available, $n$ & 5 & 35 & 1 \\
\hline DAS28 at 6 months & $3.9(3.1-7.1)$ & $2.8(2.2-3.9)$ & 5.3 \\
\hline
\end{tabular}

Conclusions: This preliminary study gives an early review of biosimilar use in the UK, showing that these drugs are used in patients with active disease as both first-line and subsequent-line biologics. Many patients with low disease activity are also being switched from originators primarily for cost reasons. Outcome data are limited but data capture will continue and updated reports from the BSRBR-RA will continue to be presented.

Disclosure of Interest: None declared

DOI: 10.1136/annrheumdis-2017-eular.3497

\section{FRI0197 ADHERENCE, SATISFACTION AND FULFILLMENT OF EXPECTATIONS OF PATIENTS WITH RHEUMATOID ARTHRITIS TREATED WITH SUBCUTANEOUS BIOLOGICALS. ARCO STUDY}

J. Calvo-Alén ${ }^{1}$, C. Marras ${ }^{2}$, I. Monteagudo ${ }^{3}$, G. Salvador ${ }^{4}$,

T. Vázquez-Rodríguez ${ }^{5}$, J. Tovar ${ }^{6}$, P. Vela ${ }^{7}$, F. Maceiras ${ }^{8}$, M. Bustabad $^{9}$,

E. Peiró ${ }^{10}$, J. Rosas ${ }^{11}$, M. Arteaga ${ }^{12}$, S. Fernández ${ }^{12}$, L. Cea-Calvo ${ }^{12}$,

Y. Mestre ${ }^{12}$, E. Raya ${ }^{13} \cdot{ }^{1} H$ Txagorritxu, Vitoria; ${ }^{2}$ HUV Arrixaca, Murcia; ${ }^{3} H G U$ Gregorio Marañón, Madrid; ${ }^{4} \mathrm{HU}$ Mútua Terrasa, Barcelona; ${ }^{5} \mathrm{HU}$ Lucus Augusti, Lugo: ${ }^{6} \mathrm{HGU}$, Elche $:{ }^{7} \mathrm{HGU}$. Alicante: ${ }^{8} \mathrm{CHU}$, Vigo: ${ }^{9} \mathrm{HU}$, Tenerife; ${ }^{10} \mathrm{HU}$ Marqués de Valdecilla, Santander: ${ }^{11} \mathrm{H}$ Marina Baixa, Alicante: ${ }^{12}$ Medical Affairs, Merck Sharp \& Dohme, Madrid; ${ }^{13} \mathrm{HU}$ San Cecilio, Granada, Spain

Background: In patients with rheumatoid arthritis (RA), we previously described that adherence to the subcutaneous (SC) biological treatment is better with monthly administration.

Objectives: We further assessed if there are differences in patients expectations and satisfaction with efficacy and tolerance that could contribute to explain such finding.

Methods: ARCO was a retrospective study on RA patients who had been prescribed a SC biological 11-18 months prior to the study. Adherence was calculated with the medication possession ratio (MPR). Satisfaction and expectations were assessed with the Spanish validated Carbonell questionnaire [1]

Results: We included 364 patients (age 54.9 years [SD 12.5], 77.5\% women, median duration of RA 7.8 years, period studied for the SC biological 14.8 months). Non-adherence (MPR $\leq 80 \%$ ) was lower in patients with monthly $(6.4 \%)$ than with weekly $(17.4 \%, \mathrm{p}=0.034)$ or every 2 weeks administration $(14.4 \%$, $\mathrm{p}=0.102$ ). The $\%$ of satisfied patients (quite/very satisfied) was $86.2 \%$ for efficacy and $64.4 \%$ for side effects or tolerance. Non-adherence was similar in satisfied with efficacy and in neutral/unsatisfied patients $(14.7 \%$ vs. $8.3 \%, \mathrm{p}=0.399)$, or in patients satisfied/not satisfied with side effects ( $13.1 \%$ vs. $15.4 \%, p=0.504)$. The fulfillment of expectations is shown in the table. With regard to expectations on the effect, non-adherence was 15.5\% (higher than expected), $12.6 \%$ (as expected) and $10.7 \%$ (lower than expected) ( $p=0.677$ ), and with regard to discomfort/side effects, it was $15.6 \%$ (greater than expected), $18.5 \%$ (as expected) and $11.1 \%$ (lower than expected, or no side effect) $(\mathrm{p}=0.189)$. Fulfilment of expectation on efficacy was similar for the 3 dosing schemes, but the \% reporting lower than expected discomfort or no discomfort was greater with fewer SC injections (table). In particular, the \% reporting no discomfort/side effects with the administration were $17.8 \%$ (weekly), $29.3 \%$ (every 2 weeks), and $35.0 \%$ (monthly) $(p=0.013$ )

\begin{tabular}{lccccc}
\hline & $\begin{array}{c}\text { All } \\
\%\end{array}$ & $\begin{array}{c}\text { Weekly } \\
\%\end{array}$ & $\begin{array}{c}\text { Every 2 weeks } \\
\%\end{array}$ & $\begin{array}{c}\text { Monthly } \\
\%\end{array}$ & $\mathrm{p}$ \\
\hline Effect of the treatment & & & & & \\
$\quad$ Much/quite higher than expected & 59.9 & 59.2 & 57.2 & 66.7 & 0.573 \\
$\quad$ More or less as expected & 32.1 & 33.6 & 33.8 & 25.0 & \\
$\quad$ Quite/much lower than expected & 8.0 & 7.4 & 9.0 & 8.3 & \\
$\begin{array}{l}\text { Discomfort } \\
\quad \text { Much/quite higher than expected }\end{array}$ & 13.0 & 15.8 & 11.5 & 10.1 & 0.048 \\
$\quad \begin{array}{l}\text { More or less as expected } \\
\text { Quite/much lower than expected or }\end{array}$ & 34.4 & 38.2 & 35.3 & 23.3 & \\
$\quad$ there were no discomfort & 52.5 & 46.0 & 53.2 & 66.6 & \\
\hline
\end{tabular}

Conclusions: RA patients on SC biological therapy show high satisfaction and fulfillment of expectations on efficacy, although both aspects lower for tolerance. Dosing regimen with lower number of SC injections seems to be associated with better fulfillment of expectations of tolerance. This finding, added to the lower number of injections itself, might explain the better adherence observed with monthly administration.

References:

[1] Carbonell J, Badia X; Grupo Expresar. Development and validation of a satisfaction questionnaire in patients with rheumatoid arthritis. Reumatol Clin 2006:2:137-45.

Acknowledgements: Funded by MSD, Spain.

Disclosure of Interest: None declared

DOI: 10.1136/annrheumdis-2017-eular.3176

\section{FRI0198 USABILITY AND SAFETY OF SB5 (AN ADALIMUMAB BIOSIMILAR) PRE-FILLED SYRINGE AND PRE-FILLED PEN IN PATIENTS WITH RHEUMATOID ARTHRITIS}

J. Ghil ${ }^{1}$, J. Niebrzydowski ${ }^{2}$, A. Zielińska ${ }^{3}$, Y. Lee ${ }^{1} .{ }^{1}$ Samsung Bioepis Co., Ltd., Incheon, Korea, Republic Of; ${ }^{2}$ Medica Pro Familia Sp. z o.o. S.K.A., Gdynia;

${ }^{3}$ Medica pro Familia Sp z o.o. S.K.A, Warszawa, Poland

Background: SB5 is developed as a biosimilar of the reference adalimumab (ADL). Equivalence in pharmacokinetics (PK) and efficacy between SB5-pre-filled syringe (PFS) and ADL-PFS has been demonstrated in a phase I and phase III study. ${ }^{1,2}$ The PK equivalence between SB5-PFS and SB5-pre-filled pen (PFP) in healthy subjects has been reported previously. ${ }^{3}$

Objectives: To compare the usability and safety of SB5-PFS and SB5-PFP from a phase II study.

Methods: This was an open-label, single-arm study in patients with rheumatoid arthritis (RA). Patients with RA self-administered a total of 6 injections of $40 \mathrm{mg}$ SB5 every other week; the first two injections were through PFS and the following four injections were through PFP. The primary objective of this study was to demonstrate comparability between PFS (at week 2) and PFP (at week 6) in terms of injection site pain score. Patients completed a pain evaluation questionnaire using an 11-point numeric rating scale at two time points (immediately and 15-30 minutes post-injection) after the first four injections. Equivalence between PFS and PFP was concluded if the $97.5 \%$ confidence interval $(\mathrm{Cl})$ of the difference in the injection site pain score was contained within the equivalence margin of \pm 5 . Other usability (overall impression and patient preference) and safety endpoints were also measured. 